\author{
Asian Journal of \\ Medical and Biological Research \\ ISSN 2411-4472 (Print) 2412-5571 (Online) \\ www.ebupress.com/journal/ajmbr
}

\title{
Article \\ Health literacy and behavior related to cancer and diabetes among higher secondary students
}

Zahidur Rahim ${ }^{1}$, Fatima Tuz Zohra Makkia ${ }^{2}$, Md. Ekramul Haque ${ }^{3}$, TA Robin ${ }^{4}$, Sumon Chandra Debnath ${ }^{5}$, Md. Abdur Rouf ${ }^{6}$, Dewan Md. Mehedi Hasan ${ }^{7}$ and Zobaid Mohammad Rahat Chowdhury ${ }^{8}$

${ }^{1}$ Senior Project Officer, National Scale-Up, Save the Children, Dhaka, Bangladesh

${ }^{2}$ Medical Officer, Sadar Upazilla, Moulovibazar, Bangladesh

${ }^{3}$ Evaluator (M\&PDC), Communicable Disease Control (CDC), DGHS, Mohakhali, Dhaka-1212, Bangladesh

${ }^{4}$ Deputy Manager, Monitoring \& Evaluation, National Scale-up, Save the Children, Dhaka, Bangladesh

${ }^{5}$ Assistant Research Officer, Bangladesh Breastfeeding Foundation, Mohakhali, Dhaka-1212, Bangladesh

${ }^{6}$ Assisant Director, Aichi Medical College Hospital, Uttara, Dhaka-1230, Bangladesh

${ }^{7}$ Medical Officer (MBPC), Hospital Service Management, DGHS, Mohakhali, Dhaka-1212, Bangladesh

${ }^{8}$ Assisant Director, East West Medical College Hospital, Uttara, Dhaka-1230, Bangladesh

*Corresponding author: Dr. Zahidur Rahim, Senior Project Officer, National Scale-up, Save the Children, Dhaka, Bangladesh. Phone: +8801725023337; E-mail: rahim.zahidur@gmail.com

Received: 07 September 2017/Accepted: 21 September 2017/ Published: 28 September 2017

\begin{abstract}
This cross sectional study was carried out among 313 higher secondary college students to assess the knowledge on health literacy and behaviors related to non communicable diseases (Diabetes and Cancer). The study period was from January to December 2013. Majorities (63\%) of the respondents were male and rests of them $(37.0 \%)$ were female. Maximum of the $(45.1 \%)$ respondent's father was higher educated (masters) and more than one-third $(34.9 \%)$ mothers were graduate. A vast majority $(98.1 \%)$ of the respondents indicated smoking as the main risk factor for Cancer in which most (89.8\%) of the respondents mentioned excess body weight as the most important risk factor for Diabetes. A vast majority (93.9\%) of the respondents gave emphasis about cessation of tobacco for the prevention of cancer whereas majority (79.9\%) of the respondents gave emphasis about physical exercise and labor for the prevention of Diabetes. Knowledge about health literacy is statistically significant $(\mathrm{p}=0.021)$ with gender of the students. Father and mother educational status were not significantly associated ( $p>0.05)$ with health literacy. Need based, specific, time relevant and school based programs and community based awareness program need to be designed for further improvement of health literacy among college students.
\end{abstract}

Keywords: health literacy; non-communicable disease; risk factor, behavior

\section{Introduction}

In Bangladesh health education is widely used term in preventive medicine directed to promote healthy lifestyle. Health professionals typically define health education as a one way approach to information dissemination. Generally they do not take into consideration the actual use of information to improve health by the individual receiving the information. Over the last few years health professionals in Bangladesh have begun to analyze the relationship between health, knowledge and environmental support to achieve a more sophisticated understanding of how to change lifestyles. These levels distinguish between compliance with expert prescribed behavior (functional health literacy), self-management of problems in partnership with health professionals (interactive health literacy), and empowerment (critical health literacy) (Jahan, 2006).

Health Literacy has been defined as the cognitive and social skills which determine the motivation and ability of individuals to gain access to, understand and use information in ways which promote and maintain good health. 
Health Literacy means more than being able to read pamphlets and successfully make appointments. By improving people's access to health information and their capacity to use it effectively, health literacy is critical to empowerment.

The World Health Organization (WHO) reports NCDs to be by far the leading cause of death in the world, representing over $60 \%$ of all deaths. Out of the 36 million people who died from NCDs in 2005, half were under age 70 and half were women. Of the 57 million global deaths in 2008, 36 million were due to NCDs. That is approximately $63 \%$ of total deaths worldwide. Risk factors such as a person's background, lifestyle and environment are known to increase the likelihood of certain NCDs. Every year, at least 5 million people die because of tobacco use and about 2.8 million die from being overweight. High cholesterol accounts for roughly 2.6 million deaths and 7.5 million die because of high blood pressure (WHO, 2013).

However, this study was aimed to measure the health literacy and behavior related to NCD the higher secondary students that can steer to a broader study all over the country.

\section{Materials and Methods \\ 2.1. Study design and settings}

This study was a cross sectional study carried out among higher secondary students in Rangpur city. Three private colleges were selected purposively. Selected college were Cantonment public school and college, Rangpur; RCCI public school and college; Police line school and college, Rangpur. This study was conducted during the period of January to December 2013.

\subsection{Study population and sample size}

College student both male and female who are willing to participate in the study consider as study population. Students were taken from eleven class (11) students and all those are attending at the class; during study period. Finally, the sample size was taken 313 . Purposive sampling was done to find the study population.

\subsection{Data collection instrument and technique}

Data were collected using semi structured self-administered questionnaire based on the objectives with simple and understandable language. The questionnaire was compiled by adapting questions from published studies with appropriate modification in this study. According to the specific objectives the variables were identified and the Bangle questionnaire was draft. Opinion and suggestions were obtained from supervisors, throughout initial period of questionnaire development. The subjects who were present at the class in data collection date. Lists of students were collected from class teacher and the list comprises of the class, name and roll number.

\subsection{Statistical analysis}

Data editing was carried out by checking and verifying the full questionnaire at the end of the interview and also at the end of whole survey before analysis. The data analysis was performed by using Statistical Package for Social Science (SPSS) version 20. We used descriptive statistics as well as chi-square test to identify relationship between health literacy and socio-economic profile of the respondents.

\section{Results}

Table 1 shows the socio-economic characteristics of the study population. Majorities (63\%) of the respondents were male and rests of them $(37.0 \%)$ were female. Maximum of the $(45.1 \%)$ respondent's father was higher educated (masters) and more than one-third (34.9\%) mothers were graduate. In occupation, $46.6 \%$ fathers were service holder and $23.6 \%$ were businessmen. However, $73.8 \%$ mothers were house maker workers and $14.4 \%$ were teacher. Majority (97.1\%) of the respondent's monthly family income was $<50000$ taka (Table 1 ).

Table 2 illustrates the life style risk factors of NCD (Cancer and Diabetes). A vast majority (98.1\%) of the respondents indicated smoking as the main risk factor for Cancer. About two-third (66.5\%) of the respondents assumed alcohol consumption was another causative factor for Cancer. On the contrary, Most (89.8\%) of the respondents mentioned excess body weight as the most important risk factor for Diabetes and more than twothird (72.5\%) assumed that less physical labor also a causative factor for Diabetes (Table 2).

Table 3 depicts the knowledge of the respondents on prevention of NCD (Cancer and Diabetes). A vast majority (93.9\%) of the respondents gave emphasis about cessation of tobacco and $60.4 \%$ mentioned regular intake of vegetable for prevention of Cancer. On the other hand, majority (79.9\%) of the respondents gave emphasis about physical exercise and labor followed by $74.1 \%$ mentioned body weight control for the prevention of Diabetes (Table 3). 
Table 1. Socio-demographic profile of the respondents $(n=313)$.

\begin{tabular}{lll}
\hline Characteristics & $\mathbf{n}$ & \% \\
\hline Gender & & \\
Male & 196 & 63 \\
Female & 117 & 37 \\
Age group (years) & & \\
15 & 27 & 8.6 \\
16 & 173 & 55.2 \\
17 & 101 & 32.3 \\
18 & 12 & 3.8 \\
Father's education & & \\
SSC and below & 21 & 6.6 \\
HSC & 34 & 10.9 \\
Diploma & 3 & 1.0 \\
Graduate & 114 & 36.4 \\
Masters & 141 & 45.1 \\
Mother's education & & \\
SSC and below & 65 & 19.9 \\
HSC & 96 & 30.7 \\
Graduate & 109 & 34.9 \\
Masters & 43 & 13.7 \\
Father's occupation & & \\
Agriculture & 12 & 3.8 \\
Service & 146 & 46.6 \\
Business & 74 & 23.6 \\
Doctor & 24 & 7.7 \\
Teacher & 46 & 14.7 \\
Others & 11 & 3.5 \\
Mother's occupation & & \\
Service & 30 & 9.6 \\
Business & 7 & 2.2 \\
Teacher & 45 & 14.4 \\
House maker & 231 & 73.8 \\
Monthly family income & & \\
<50000 & 304 & 97.1 \\
50001-100000 & 7 & 2.2 \\
$>100000$ & 2 & 0.6 \\
\hline & & \\
& & \\
& &
\end{tabular}

Table 2. Knowledge on life style risk factors of NCD* (Cancer, Diabetics).

\begin{tabular}{lll}
\hline Life style risk factors of NCD & n & \% \\
\hline Cancer & & \\
Smoking & 307 & 98.1 \\
Betel nut with jarda & 184 & 58.8 \\
Alcohol consumption & 208 & 66.5 \\
Different colorful drink & 97 & 31 \\
Chemical mixed fruit & 159 & 50.8 \\
Chemical mixed vegetable & 156 & 49.8 \\
Diabetics & & \\
Smoking & 44 & 14.1 \\
Mental pressure & 99 & 31.6 \\
Excess body weight & 281 & 89.8 \\
Less physical labor & 227 & 72.5 \\
Under nourished food intake & 103 & 32.9 \\
\hline
\end{tabular}

* NCD $=$ Non Communicable Disease 
Table 3. Knowledge on prevention of NCD (Cancer, Diabetes).

\begin{tabular}{lcc}
\hline Characteristics of preventive measure & n & \% \\
\hline Cancer & 294 & 93.9 \\
Cessation of tobacco use & 160 & 51.1 \\
Give up chemical mixed drink & 189 & 60.4 \\
Regular intake of vegetable & 113 & 36.1 \\
Regular physical exercise and labor & 101 & 32.3 \\
Limited use of electronics & & \\
Diabetics & 206 & 65.8 \\
Change food habit & 250 & 79.9 \\
Physical exercise and labor & 231 & 73.8 \\
Disciplined life style & 232 & 74.1 \\
Body weight control & 113 & 36.1 \\
Reduce mental pressure & 111 & 35.5 \\
Medicine intake & \\
\hline
\end{tabular}

Table 4. Relationship between knowledge about health literacy and socio-economic profile.

\begin{tabular}{|c|c|c|c|c|}
\hline \multirow[t]{2}{*}{ Variables } & \multicolumn{3}{|c|}{ Knowledge about health literacy } & \multirow[t]{2}{*}{ Test statistics } \\
\hline & Poor & Average & Good & \\
\hline $\begin{array}{l}\text { Gender } \\
\text { Male }\end{array}$ & $20(10.2 \%)$ & $66(33.7 \%)$ & $110(56.1 \%)$ & $\chi^{2}=7.742$ \\
\hline Female & $9(7.7 \%)$ & $58(49.6 \%)$ & $50(42.7 \%)$ & $\begin{array}{c}\mathrm{df}=2 \\
\mathrm{P}=0.021^{*}\end{array}$ \\
\hline $\begin{array}{l}\text { Father's education } \\
\text { Below graduate }\end{array}$ & $5(8.9 \%)$ & $26(46.4 \%)$ & $25(44.6 \%)$ & $\chi^{2}=1.367$ \\
\hline Graduate \& above & $24(9.3 \%)$ & $98(38.1 \%)$ & $135(52.5 \%)$ & $\begin{array}{c}\mathrm{df}=2 \\
\mathrm{P}=0.505\end{array}$ \\
\hline $\begin{array}{l}\text { Mother's education } \\
\text { Below graduate }\end{array}$ & $15(9.3 \%)$ & $62(38.5 \%)$ & $63(39.1 \%)$ & $\chi^{2}=0.176$ \\
\hline Graduate $\&$ above & $14(9.2 \%)$ & $62(40.8 \%)$ & $68(44.7 \%)$ & $\begin{array}{c}\mathrm{df}=2 \\
\mathrm{P}=0.916\end{array}$ \\
\hline
\end{tabular}

Table 5. Opinion of respondents about snacks and junk food intake.

\begin{tabular}{lll}
\hline Name of the variables & $\mathbf{n}$ & $\mathbf{\%}$ \\
\hline Snacks & & \\
Oil contained food & 193 & $61.7 \%$ \\
Fast food or junk food & 90 & $28.8 \%$ \\
Fruit & 136 & $43.5 \%$ \\
Any type of drink & 105 & $33.5 \%$ \\
Bakery product & 178 & $56.9 \%$ \\
Frequency of Junk food intake & & \\
Everyday & 29 & $9.3 \%$ \\
Any occasion & 67 & $21.4 \%$ \\
Every now and then & 210 & $67.1 \%$ \\
Do not take & 7 & $2.2 \%$ \\
\hline
\end{tabular}

Table 4 represents the association of level of knowledge about health literacy among respondents with their gender, father's \& mother's educational status by Pearson's Chi-square method. According to table $56.1 \%$ of male \& $42.7 \%$ females had good knowledge score in health literacy, $49.6 \%$ of females \& $33.7 \%$ of male had average knowledge score \& rest of them were in group of poor knowledge score. So knowledge about health literacy is statistically significant $(\mathrm{p}=0.021)$ with gender of the students. Whereas, father's educational status has no association ( $p>0.05)$ with knowledge about health literacy of students and there is no association $(p>0.05)$ between mother's educational status with health literacy knowledge of students (Table 4).

Table 5 shows that opinion of respondents about taking snacks and frequency of taking junk food. More than half $(61.7 \%)$ of the respondents mentioned oil contained meal as snacks. About $56.9 \%$ of the respondents 
mentioned bakery food while $28.8 \%$ mentioned fast food or junk food as snacks. Table also showed that more than two-third (65.73\%) of the respondents mentioned that they intake junk food every now and then. About 9.3\% stated that they intake junk food every day (Table 5).

\section{Discussion}

Health literacy has five components. Among the component theoretical knowledge consist of communicable disease, non-communicable disease and primary health care. The present study focused on NCD and behavior related to it. There are two conceptual models for health literacy measurement. Model-1 showed Causal pathways between limited health literacy and health outcomes (Paasche and Wolf, 2007) and Conceptual model2 described the relationship among individual capacities, health-related print and oral literacy, and health outcomes (Baker, 2006).

The present study found that knowledge about health literacy is statistically significant $(\mathrm{p}=0.021)$ with gender of the students. Whereas, father's educational status has no association $(p>0.05)$ with knowledge about health literacy of students and there is no association $(p>0.05)$ between mother's educational status with health literacy knowledge of students.

Above findings are represents that female are still backward position in comparison with male. Worldwide, men are more likely to be literate, with 100 men considered literate for every 88 women (BBC, 2005). Ratio of female to male secondary enrollment (\%) in Bangladesh was last measured at 115.35 Ratio of female to male secondary enrollment is the percentage of girls to boys enrolled at secondary level in public and private schools (World Bank, 2011). In Germany and other industrialized nations, health problems are more prevalent among children and adolescents with a low social background. This association may, at least partially, be mediated by health literacy (Schmidt et al., 2010).

In our study viewed that a vast majority $(98.1 \%)$ of the respondents indicated smoking as the main risk factor for Cancer. About two-third (66.5\%) of the respondents assumed alcohol consumption was another causative factor for Cancer. A similar kind study on different features regarding cancer was conducted among teenager's students in Gauteng, South Africa in 2001. Among the students $48.6 \%$ had previously received cancer information while other indicated that they had a family history of cancer $(23.6 \%)$. Significantly more females reported having received cancer information or having a history of cancer in the family than males $(\mathrm{p}<.001)$. However average knowledge scores among the students were low. Transvaal Education Department also has better knowledge of the signs and symptoms and etiology of the five cancers included in the questionnaire. The number of pupils who indicated that smoking was important to them was $27 \%$. From their study they concluded that, students in grade 10 living in Gauteng are not well informed on the etiology, signs and symptoms of cancer or cancer risk (Botha, 2001).

The present study viewed that most $(89.8 \%)$ of the respondents mentioned excess body weight as the most important risk factor for Diabetes and more than two-third (72.5\%) assumed that less physical labor also a causative factor for Diabetes. An article was published in Bahrain Medical Bulletin which contained the queries on knowledge related with diabetic's definition, risk factors, symptoms, complications and preventive measures. Risk perception for diabetes was also covered in their study. Given that the prevalence of diabetes has increased drastically in Oman over the decades, health promotion seems essential, along with other means to prevent and control this emerging health problem (Al-nasir, 2003).

The present study showed that more than half $(61.7 \%)$ of the respondents mentioned oil contained meal as snacks. About $56.9 \%$ of the respondents mentioned bakery food while $28.8 \%$ mentioned fast food or junk food as snacks. Table also showed that more than two-third (65.73\%) of the respondents mentioned that they intake junk food every now and then. About $9.3 \%$ stated that they intake junk food every day. A recent study showed the dietary changes with progressing of globalization. Animal-source food changes are equally dramatic, particularly in selected countries. In China, we documented very large increases in animal-source food intake. Egg, poultry, beef, and pork consumption have increased rapidly in China, and milk intake has recently begun to rise. Today, the average Chinese adult consumes $>1300 \mathrm{kcal} / \mathrm{d}$ of pork, poultry, beef, mutton, fish, eggs, and dairy foods. As we showed elsewhere, the structure of consumption shifts in China is such that for each additional increase in income, adults proportionally increase their intake of animal-source foods Concurrent shifts are occurring in the use of caloric sweeteners. Only a few countries have published studies of the trends concerning the specific foods in which caloric sweeteners are found; the United States and South Africa are 2 of these countries. In the United States, calorically sweetened beverages (e.g., soft drinks and fruit drinks) account for $>50 \%$ of the increase in added caloric sweeteners in the past several decades; the foods responsible for caloric sweetener intake in South Africa are much more varied than in the United States (Popkin, 2006). 


\section{Conclusions}

This is the first study in Bangladesh related to health literacy and behavior related to non communicable disease (Cancer and Diabetes) among college students. The majority respondents had positive answered about taking fast food frequently. Knowledge about health literacy was statistically significant with gender of the students. Need based, specific, time relevant and school based programs and community based awareness program need to be designed for further improvement of health literacy among college students.

\section{Acknowledgement}

The authors are thankful to the study participants who willingly took part in the data collection procedure.

\section{Conflict of interest}

None to declare.

\section{References}

Bohlman LN, 2001. Health literacy: a prescription to end confusion. Institute of Medicine of National Academia, 1-25.

Baker DW, 2006. The meaning and measure of health literacy. Journal of General Internal Medicine, 21: 878883.

Botha A, 2001. Knowledge, attitudes, beliefs and practices of school going adolescents living in Gauteng in relation to common cancers and cancer risks. Msc dissertation, University of Pretoria, Pretoria.

World Bank report, 2011. Education enrollment in Bangladesh.

Faisal A and A Latif, 2003. Assessment of knowledge of diabetes mellitus among Bahraini school teachers. Bahrain Medical Bulletin, 25:4.

Jahan RA, 2000. promoting health literacy: a case study in the prevention of diarrheal disease from Bangladesh. Health Promotion International, 15: 285-291.

Pcheaas and Wolf, 2007. The causal pathways linking health literacy to health outcomes. American Journal of Health Behavior, 31: 19-26.

Popkin BM, 2006. Global nutrition dynamics: the world is shifting rapidly towards a diet linked with non communicable disease. The American Journal of Clinical Nutrition, 84: 289-298.

Schmidt CO, 2010. Health related behavior, knowledge, attitudes, communication and social status in school in eastern Germany. Health Education Research, 25: 542-551. 